\title{
Inmunidad de María de la culpa original
}

(II)

Vamos a clasificar sus argumentos, siguiendo así en cierto sentido el mismo orden que él usa, en cuatro grupos: argumentos o pruebas de razón, de Tradición, de Sagrada Escritura y de Liturgia.

Argumentos de razón.

Como base y compendio de la argumentación, Tomás de Strasbourg toma la fórmula clásica y tradicional desde Eadmero: "Potuit, decuit, ergo fecit" " , que nuestro autor trata ampliamente, estudiando por separado la posibilidad y la conveniencia de la preservación de María de la culpa original, de las que deduce, a modo de corolario, el hecho de la Inmaculada Concepción de María.

74 Eadmaro, 1.604-1.124, monje benedictino y discípulo de San Anselmo, expuso la doctrina sobre la Inmaculada en su obra Tractatus de Conceptione $B$. Mariae Virginis, PL. 159, 401-318, donde está enumerada entre las obras de San Anselmo. La paternidad eadmeriana fue vindicada por Ragey, atribución confirmada posteriormente por Thurston y Slater Cfr. B. HeuRTEBIzE: "Eadmer" D. T. C., IV/2, París 1924, 1.976 ss., X. LE BACHeLET, “Immaculée Conception" D. T. C., VII/1, París 1927, 1.007; F. M. MILDENER, "The Immaculate Conception in England up to the time of John Duns Scoto": Mar. 1 (1939) 206-215.

El pasaje que contiene la fórmula clásica es el siguiente: "...non potuit dare corpori humano, quod ipse sibi parabat templum in quo corporaliter habitaret, et de quo in unitate suae Personae perfectus homo fieret, ut licet inter spinas peccatorum conciperetur, ab ipsis tamen spinarum aculeis omnimode exsors redderetur? Potuit plane. Si igitur voluit, fecit". (EADMarus, Tractatus de Conceptione B. Mariae Virginis, PL. 159, 305). Cfr. L. ERRIQuez, L'Immacolata nel Tractatus de Conceptione S. Mariae di Eadmaro, Bari 1958; G. GEENEN, "Eadmer, le premier theologien de l'Immaculée Conception": Virgo Immaculata, 5 Academia Mariana Internationalis, Roma 1955, 90-136.

La expresión de Eadmaro;" "potuit, decuit, ergo fecit", fue posteriormente aceptada y ampliada por diversos autores para afirmar el privilegio concepcionista y la santificación de María. Así, por ejemplo, se encuentra en Guillermo de Ware, Enrique de Gante, Juan Duns Scoto, Pedro Aureolo, Francisco Mayron, Durando de Saint Pourcain, Juan de Nápoles, Erveo Natal, Pedro d'Aquila, Hermann de Schildizs, Marsilio d'Inghem, Gabriel Biel, etc. 
"Quantum ad primum, primo ponam duas conclusiones. Prima est, quod Deus potuit Virginem matrem praeservare ab originali culpa. Secunda, quod hoc congruum fuit, et divinam bonitatem decuit. Tertio infero unum corollarium, scilicet, quod de facto Virgo mater Dei sine peccato concepta fuit" 75 .

1. Dios pudo preservar a la Virgen María de toda mancha original.-La prueba de la posibilidad que nos ofrece Tomás de Strasbourg está relacionada con la doctrina sobre la transmisión del pecado original. Su originalidad, sin embargo, no es patrimonio del Argentinense. Ya anteriormente había sido propuesta por algunos teólogos, v. gr., Gerardo de Abbeville ${ }^{76}$ y Guillermo de Ware ${ }^{77}$, para afirmar la posibilidad de la preservación de María de la culpa original. Después del Argentinense, aún recurren a ella Marsilio d'Inghem ${ }^{78}$ y Gabriel Biel ${ }^{79}$, mientras otros

75 In 3 Sent., d. 3, q. 1, a. 1.

76 El texto a que hacemos referencia adjudicado a Gerardo de Abbeville, 1.269 , y publicado por GLORIEUX en su estudio "Une question inédite de Gerard d'Abbeville sur l'Inmmaculée Conceptión": Rech. theol. anc. mediev. 2 (1930) 275 , dice así: "Istud non oportet ponere, scilicet, quod aliter non potuerit... quia potuit semen illud ex quo formatum est corpus Virginis, purgari a Deo si voluisset, antequam anima illi uniretur et sic nullum peccatum contraheret... Ergo potuisset Deus, si voluisset, praeservare a peccato originali de potentia sua absoluta". Cfr. además A. DENEFFE, "Deux questions medievales concernant l'Immaculée Conception": Rech. theol. anc. mediev. 4 (1932) 314.

77 GuILlermo DE WARE, $\uparrow 1300$, maestro de J. Duns Scoto, de quien depende en parte nuestro autor, enuncia así el argumento: "Possibilitatem ostendo sic: primo narrando, secundo exempla adducendo. Primo narrando sic: illa massa carnis, ex qua corpus Virginis fuit formatum, simul fuit seminata et mundata. Ex parte autem seminantis fuit in ea qualitas morbida; sed eatenus, qua fuit inde formandum corpus, fuit mundata, non sanctificata, quia sanctificari non potest nisi quod est susceptivum peccati et gratiae, cuiusmodi est sola anima. In massa, inquam, illa fuit ratione protoparentum seminantium qualitas morbida, ratione cuius qualitatis ex unione animae ad carnem talem in aliis hominibus contrahitur originale. Cum igitur infectio ista sive qualitas morbida non sit substantia carnis, sed reatus differens ex ea, possibile fuit a Deo praeservare illam massam ab infectione vel qualitate morbida in quantum ex ea debuit forma-

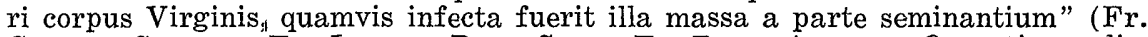
Guielmi Guarrae, Fr. JoAnNis Duns Scotr, Fr. Petri Aureoli, Quaestiones disputatae de Immaculata Conceptione Beatae Mariae Virginis. Bibliotheca Franciscana Scholastica Medii Aevi 3, Ad Aquas Claras-Quaracchi 1904, 5).

78 MARSILlo D'INGHEN, $\uparrow 1396$, que en esta cuestión copia en su mayor parte a Tomás de Argentina, a quien enumera entre los defensores de la Inmaculada, escribe: "...quamvis semen infusum ex libidinosa coniunctione parentum fuisset tale quod ipsum sic susceptum esset natum maculare animam sibi coniunctam, posset enim postea a Domino purgari ab hac macula vel tempore medio vel etiam in animae infussionem quod simul semen vel corpus formatum et sic organizatum ex eodem a concupiscentia mundaret et animam cum gratia sibi infunderet; tunc enim animam nunquam fuisset originaliter rea, sed semper Deo grata...".

"Secundo quia potuit praeservare semen a qualitate morbida ex qua surgit animae cum sibi unitur originalis culpa..., etc." (Quaesiones super 2 Librum Sententiarum, d. 20, a. 2).

79 GABRIEL BrEL, 1425-1495: “Nam quod Virgo potuit ab originali peccato 
se conformaron con citarla o la rechazaron como explicación insuficiente ${ }^{80}$.

Dios —dice el "Doctor Fácil"-, por su potencia infinita, pudo preservar el semen, por el que se propagó y tuvo origen María, de aquella infección o "qualitas morbida" que le es comunicada y adquiere en la generación, y es causa del pecado original en el alma, en el acto de la animación.

"Deus potuit semen, quo Virgo propagata est, praeservare a qualitate morbida, ex cuius conexione foetus inficitur originali macula; ergo potuit Virginem praeservare ab huiusmodi macula" 81 .

Tomás de Strasbourg se siente seguro de su afirmación y para confirmarla aduce primeramente varias razones y después resuelve dos dificultades, insistiendo siempre en la acción preventiva o preservativa de Dios.

El primer término o antecedente, "Dios pudo preservar el semen del que había de nacer María de la qualitas morbida", lo prueba y consolida nuestro autor con tres argumentos. El primero se funda en la absoluta soberanía y poder divinos, que pueden separar una entidad o cosa que es primera de otra que es posterior. $\mathrm{Y}$ esto con mayor razón si esa entidad primera es simpliciter absoluta, cual es el semen, que natural-

praeservari: nullus sanae mentis negare potest: nam potuit Deus conceptum semen a morbida qualitate praeservare ne inficeret... Potuit et tollere omnem fervorem libidinis in seminatione unde illa morbida qualitas generatur..." (In 3 Sent., d. 3, q. 1, a. 2).

80 J. DuNS ScoTo, $\dagger 1308$, recoge esta explicación, pero no la da importancia, antes bien parece rechazarla. (Cfr. C. BALIC, Joannis Duns Scoti, Doctoris mariani. Theologiae Marianae elementa, Sibenici 1933, 27-28, 49, 193, 213); PEDRo AUREolo, +1322 , en su obra In 3 Sent., d. 39, a. 3, la propone como un medio plausible de probar la posibilidad de la Inmaculada, mientras que en el Tractatus de Conceptione B. Mariae Virginis, c. 2 la descarta completamente. (Cfr. Fr. Guilielmi Guarrae..., Fr. Perri Aureoli, Quaestiones disputatae de Inmaculata..., 48-49).

Tampoco es aceptada por PEDRo TOMÁs, $\dagger 1350$, en Liber de innocentia Virginis Mariae, I. 1, pars. 2, c. 4 (Cfr. P. ALVA Y AsToRgA, Monumenta antiqua seraphica pro Immaculata Cnceptione V. Mariae..., Lovanii 1665, 218); FRANCISCO DE MAYRon, $\dagger 1327$, en su obra Tractatus de Conceptione B. Mariae Virginis, a. 10 (Cfr. P. Alva Y AstorgA, o. c., 289-290; J. JuRIC, "Franciscus de Mayronis Immaculatae Conceptionis eximius vindex": Stud. franc. 51 (1954) 247); Durando de Saint-Pourcain, 1322, en su obra In 3 Sent., d. 3, q. 1; PeDro DE CANDIA, 1410, en De Conceptione B. Mariae Virginis tractatus seu quaestio (Cfr. P. Alva y Astorga, o. c., 191 ss.).

Sin embargo es plenamente aceptada y defendida por JUAN VITALIS, $\$ 1394$ en su obra De Conceptione B. Mariae Viriginis tractatus, 1. 3, q. 1 (P. Alva \& Astorga, o. c., 123).

81 In 3 Sent., d. 3, q. 1, a. 1 concl, 1 , 
mente es anterior a la "qualitas morbida" contraída por el pecado del primer hombre ${ }^{82}$.

Conociendo, por otro lado, el misterio de la unión o unidad hipostática, el misterio del Dios-Hombre, el Argentinense razona así: mayor y más íntima es la conexión de la naturaleza al propio supuesto que la conexión del semen humano a la "qualitas morbida". Y, sin embargo, Dios puede - lo ha hecho- separar del propio supuesto la naturaleza humana, previniendo la propia personalidad ${ }^{83}$.

Por parte de Dios - argumento metafísico- la posibilidad del privilegio no presenta ninguna repugnancia, ya que Dios, como agente principal, es omnipotente y obra independientemente de todo agente instrumental en cuanto a la substancia y a los accidentes de su efecto. $Y$ puede hacer todo aquello que no implica contradicción ${ }^{84}$. Y que Dios sea agente principal e independiente está obligado a admitirlo en toda su extensión cualquier cristiano, dice Tomás de Strasbourg.

Muchos teólogos de su centuria y principalmente de la anterior, contrarios al privilegio, veían una contradicción en que un hombre naciera después del pecado de Adán por generación natural sin incurrir en la culpa hereditaria. Toda la descendencia humana nace privada de la justicia original y con el débito de tenerla, pues se hizo deudora de ella en Adán, su cabeza y principio. Los hombres, pues, primero se propagan, nacen en pecado que en gracia ${ }^{85}$.

82 “Antecedens probo: quia virtute divina prius potest separari a posteriori, maxime si ipsum prius est entitas simpliciter absoluta; sed semen est naturaliter prius illa morbida qualitate contracta ex peccato primi hominis, et est entitas simpliciter absoluta: ergo, etc." (Ibid., ratio 1).

83 "Praeterea, confirmo illud antecedens sic. Maior et connaturalior est conexio naturae ad proprium suppositum, quam humani seminis ad illam morbidam qualitatem; sed Deus potest naturam humanam separare a proprio supposito, ipsam suppositationem praeveniendo: ergo, etc. (Ibid., ratio 2).

84 "Praeterea, agens principale totaliter independens ab agente instrumentali quantum ad substantiam, et accidentia sui effectus, sive instrumentum sit sanum, sive aegrum, aequaliter potest producere effectum perfectum... Sed Deus est agens principale totaliter independens ab agente instrumentali quantum ad substantiam et accidentia sui effectus: ergo, etc. Istam minorem tenetur quilibet christianus concedere quantum ad omnes partes suas" (Ibid., ratio 3).

85 Así resume nuestro autor las objeciones de sus contemporáneos: "Dicunt enim quidam, quod contradictionem implicat, post lapsum primi hominis aliquem nasci per naturalem propagationem sine originali peccato: quia quae sunt simul natura, quocumque unum est prius, et alterum: sed in apto nato habere gratiam, et non habente, simul natura est carentia gratiae et culpa. Cum igitur omnes homines naturaliter propagati prius habuerint carentiam gratiae, quam gratiam: quia carentia gratiae conveniebat ipsis ex se, gratia autem a principio extrinscco: ergo prius habuerunt culpam, quam gratiam.

Praeterea, posita causa sufficiente de necessitate ponitur effectus; sed carentia originalis iustitiạe cum debito habendi eam, vel est ipsa originalis culpa, 
Contestando a las dificultades, Tomás de Argentina adelanta una idea: implicaría contradicción la preservación del pecado original si atendiéramos a la causa natural y finita. Pero no con respecto a la causa sobrenatural e infinita, que puede infundir en un sujeto el hábito de la gracia desde el primer momento de su existencia. Es la varita mágica con que previene y deshace las afirmaciones de los adversarios del privilegio inmaculista de María.

"Sed ista non concludunt: quia quamvis implicaret contradictionem reducendo in causam naturalem, et finitam illam praeventionem originalis maculae, nullam tamen implicat contradictionem respectu causae supernaturalis infinitae" 86 .

Fundado en su concepción de la justicia original, de la que excluia la gracia santificante, replica que no implica contradicción el carecer por sí de la gracia y el tenerla por otro en el mismo instante, simultáneamente. Y eso sucedió en María: dado que por sí misma y conforme a su naturaleza carecía de gracia, por disposición divina jamás se vio privada de ella. Dios, causa extrínseca, pero de poder infinito, se la infundió en el primer instante de su existencia.

"Ad primum igitur, quod susceptivum privationis et habitus naturaliter est prius utroque, ideo quamvis Deus sit causa extrinseca; tamen quia est potentiae infinitae, potest subiectum ponere sub habitu gratiae in primordio suae naturae, ita quod nec tempore, nec instanti praefuerit sub privatione. Etiam minor non est vera: quia primus homo habuit carentiam gratiae etiam antequam peccaret $t_{n}$ ut probavi in secundo libro, et fuit aptus ad eam recipiendam, et tamen nullam habuit culpam.

Nec etiam habere ex se carentiam gratiae contradicit ei, quod est habere gratiam ab altero; immo simul stat cum eo in eodem instanti: sicut ergo materia naturaliter prius est in formis, quam formata, et tamen numquam est sine forma: Sic dato quod Beata Virgo ex se et expensatis propriis viribus fuisset informis et sine gratia, tamen ex Dei ordinatione numquam fuit sine gratia" 87 .

En la solución a la segunda dificultad, Tomás de Strasbourg, poniendo una vez más de relieve el poder y la bondad divinas, puntualiza

vel est sufficiens causa eius. Cum igitur omnes naturaliter ab Adam descendentes de necessitate nascantur cum carentia originalis iustitiae cum debito habendi eam; perdidit enim Adam huiusmodi iustitiam pro se, et pro omnibus suis posteris: ergo, etc." (Ibid., contra primam conclusionem).

86 Ibid., contra obiectiones primae conclusionis.

87 Ibid., solutio obiectionum primae conclusionis, ad, 1. 
y perfila los conceptos de sujeto y momento de la preservación de María de la culpa original. Dios puede absolver a cualquier alma, en el primer instante de su existencia ${ }^{88}$, de la obligación de poseer la justicia original. O puede crearla inmune y libre de la culpa original ya desde el primer momento de su existencia, del mismo modo que la libra posteriormente mediante el bautismo de agua, de sangre o de fuego. En nuestro caso, María pudo ser inmune del pecado original desde el primer momento de su existencia, al serle infundida el alma en su cuerpo, si Dios la perdonó y la absolvió de la deuda original.

"Ad secundum dicendum, quod Deus posset, si vellet, quamcumque animam in primordio suae creationis absolvere a debito habendi iustitiam originalem, sicut in succesu temporis ipsam absolvit mediante baptismo fluminis, sanguinis vel flaminis, et per consequens talis anima non minus esset immunis ab originali culpa, quam anima hominis baptizati.

Etiam potest dici ad maiorem, quod posita causa sufficienti, adhuc Deus potest suspendere effectum, ne eveniat" 89 .

\section{Fue conveniente que el Hijo de Dios preservara a su Madre, la} Virgen María, del pecado original.

"Secunda conclusio est, quod decuit Dei Filium Virginem Matrem ab huiusmodi macula praeservare" 90 .

Dos razones ofrece Tomás de Strasbourg para probar esta conveniencia o decencia. Son, poco más o menos, las aducidas por los teólogos de su tiempo, favorables al privilegio inmaculista, para probar esta congruencia o conveniencia ${ }^{91}$.

88 Respecto a la creación del alma y su infusión en el cuerpo, Tomás de Argentina afirma que, aunque no es imposible que Dios cree un alma antes de producirse el cuerpo, sin embargo de hecho ninguna ha sido creada antes:

"Dico breviter, quod anima intellectiva producitur sola creatione..." (In 2 Sent., d. 19, q. 1, a. 3):

"Non est impossibile animam rationalem esse ante productionem sui corporis..." (Thomas DE ARgenTINA, Ibid., d. 17, q. 1, a. 4, concl. 1);

"Nec animam primi hominis, nec animae ceterorum hominum fuerunt productae ante corporis humani productionem..." (Ibid., concl. 2).

89 In 3 Sent., d. 3. q. 1, a. 1, solutio obiectionum primae conclusionis, ad 2.

90 Ibid., concl. 2.

91 Se encuentran ya en Gerardo de Abbeville, quien, si bien niega el privilegio inmaculista, las pone en boca de los defensores de la Inmaculada (Cfr. P. GLorraux, "Une question inédite de Gerard d'Abbeville sur l'Immaculée Con ception": Rech. theol. anc. mediev. 2 (1930) 270). También son propuestas por Guillermo Ware, de quien depende en gran parte nuestro autor, en estos términos: ",..quia deçet filiụm matrem summe honorare; et quod potuit, congruum 
La primera es un argumento de razón, fundado en la Sagrada Escritura. Siendo Cristo el Hijo de Dios y, por lo tanto, la misma pureza en persona, convenía que su Madre fuera también pura en extremo, la más pura y santa de las criaturas. Más aún; Cristo estaba obligado estrictamente por precepto divino a preservarla de la culpa original, ya que todo hijo debe honrar y socorrer siempre a su madre cuando ésta se halla en peligro. $Y$ la gloria y pureza de María corrían un grave riesgo.

"Hoc decuit Dei Filium in propria matre observare, ad quod obligatur quilibet purus homo ex praecepto divino; sed quicumque filius posset matrem suam praeservare etiam a minori malo, quam fuerit originalis culpa, ipse ad hoc tenetur ex praecepto divino: quia alias non honoraret matrem, nec in maxima necessitate ei subveniret: ergo, etc." 92 .

El Verbo encarnado, pues, no hubiera hecho lo necesario al honor debido a su Madre si, pudiendo preservarla de la suma ignominia del pecado original, no lo hubiera hecho.

En realidad, Tomás de Strasbourg pasa sin querer de una razón de conveniencia o decencia a una quasi-obligación, para convalidar y dar mayor fuerza a la prueba de su corolario: de hecho fue preservada del pecado original. Pero esto no quiere decir que nuestro autor admita en Dios, en Cristo, un deber o una necesidad de preservar a María de la culpa original, ya que todo lo que ha hecho Dios por María es obra del beneplácito divino.

Como segundo argumento de conveniencia, Tomás de Argentina recoge un texto de San Anselmo, que encuadra perfectamente como

fuit quod fecerit; et hoc sequitur quod ita fecerit, cum filius debeat matrem honorare" (Fr. GULIELmi GUARRAE, Quaestiones disputatae de Immaculata, p. 6). También recurren a estos argumentos los teólogos PEDRO TOMÁs, Liber de innocentia Virginis Mariae, l. 2, pars. 2, c. 3 (Cfr. P. Alva y Astorga, Monumenta antiqua seraphica..., 230); FRANCISCo DE MAYRoN, Tractatus de Conceptione B. Mariae Virginis, a. 9 (Cfr. P. Alva Y Astorga, o. c., 288); J. JURIC, "Franciscus de Mayronis Immaculatae Conceptionis eximius vindex": Stud. franc. 51 (1954) 254-255); MARSILIo DE INGHEN, que los recoge de Tomás de Argentina y los amplía a su modo en su obra Quaestiones super II Sententiarum, d. 20, a. 2; GABRIEL BIEL, In 3 Sent., d. 3, q. 1, a. 2, etc.

92 Ibid., concl. 2. Con relación a este argumento de Tomás de Argentina, tratando de su valor e importancia, alguien ha escrito: "Sed et Gabriel Biel et Thomas de ARgentina in $3 \mathrm{~d}$. 3 ad probandum Beatam Virginem non contraxisset originale peccatum illud probant ratione illius praecepti: Honora patrem et matrem tuam. Apud quos haec consequentia fit (vel sit) valore quam apud me. Si Christus non praeservasset Matrem violaret illud praeceptum: Honora patrem et matrem..." (Dilutio quindecim argumentorum, quae quidam adversus Declamationem Fr. Ludovici Carvajali, Parisiis eidem Ludovico obiecit, publicado por Alva y Astorga en su obra Monumenta antiqua seraphica..., 514). 
prueba de congruencia del privilegio concepcionista ${ }^{93}$. Relegamos, para no repetirnos, su exposición al apartado de las pruebas o argumentos de Tradición, recogidos por nuestro autor para confirmar sus conclusiones favorables a la Inmaculada.

A continuación el "Doctor Fácil" recoge una objeción de los adversarios a la tesis inmaculista. No es conveniente ni decente rebajar la dignidad y preeminencia de Cristo, atribuyendo a María prerrogativas y dignidades singulares que no tienen igual entre las criaturas y la equiparan al Salvador de la humanidad. Solamente Cristo estuvo exento del pecado original ${ }^{94}$.

Con la precisión y sencillez que le son propias, Tomás de Strasbourg pulveriza la fuerza aparente del argumento de los maculistas con éste otro más breve: las prerrogativas de Cristo le pertenecen personalmente por propia virtud o poder; las de María son gracias o privilegios que Dios le ha concedido.

"Sed nec illud valet: quia Christus" per suam propriam potestatem, cum fuerit Deus et homo, immunis erat a peccato. Sed Virgo non sua propria potestate, sed virtute divina praeservata fuit a peccato" 95 .

3. Dios de hecho preservó a María del pecado original.-Delineadas ya perfectamente la posibilidad de la preservación de María de la mácula original y la conveniencia o congruencia de tal preservación, Tomás de Strasbourg formula razones y pruebas teológicas para llegar a la conclusión de que de hecho Dios la preservó de la culpa original. Primeramente observa que la inmunidad de pecado original aparece como parte integrante de aquel océano inmenso de gracia que constituye la santidad de María. Si la Maternidad divina exigía la perfecta virginidad de cuerpo, con mayor razón debía exigir la perfecta virginidad

93 Se trata del texto siguiente: "Decens erat ut ea puritate, qua maior sub Deo nequit intelligi, Virgo illa niteret, cui Deus Pater unicum filium, quem de corde suo aequalem sibi genitum tanquam seipsum diligebat, ita dare disponebat, ut naturaliter esset unus idemque communis Dei Patris et Virginis Filius, et quam ipse Filius substantialiter facere sibi matrem eligebat..., etc." (S. ANSELMUS, De conceptu virginali et originali peccato, c. 18: PL. 158, 451).

94 "Contra secundam conclusionem arguunt sic. Si Virgo Maria non fuisset concepta originali peccato, cum numquam commiserit actuale peccatum, tunc quantum ad immunitatem peccati fuisset aequalis gradus et dignitatis sicut humanitatis Christi; sed hoc Deus non decuit, scilicet facere aliquam creaturam, respectu cuius Christus praerogativam non haberet" (Ibid., contra secundam conclusionem).

95 Ibid., solutio ad obiectionem secundae conclusionis. 
y santidad de alma. Pudo ser y convenía que María fuera, desde su concepción, santa e inmaculada; luego lo fue. Este es el corolario o conclusión que deduce de los argumentos anteriores.

"Tertio infero unum corollarium, scilicet quod de facto Virgo mater Dei sine peccato concepta fuit" 96 .

Haciéndose eco del dicho o sentencia de San Anselmo, "quod minimum inconveniens apud Deum est impossibile" 97, el Argentinense perfila las pruebas del hecho de la preservación de María de la culpa original. Argumenta así:

"Ad probationem corollarii suppono cum Anselmo quod minimum inconveniens apud Deum est impossibile.

Tunc arguo: Illud quod decet aliquem facere, et nullam habet de impotentia excusationem, si hoc non facit, aliquo modo pro inconveniens sibi poterit imputari: sed Virginem praeservare ab onni macula Dei filium decuit, ut patet ex secunda conclusione, et ipse hoc potuit, ut patet ex prima conclusione: ergo aliquo modo inconveniens esse videtur, quod hoc non fecerit, et per consequens impossibile, ut ex propositione Anselmi patuit" 98.

Con la autoridad de San Agustín da por terminada la prueba de su corolario para pasar después a defender su tesis inmaculista contra las innumerables objeciones de los adversarios del privilegio. Texto agustiniano ${ }^{99}$ que él analiza detenidamente y lo interpreta favorablemente a su tesis. Lo estudiaremos más adelante, en las pruebas de Tradición.

Tomás de Strasbourg sabe que principalmente contra este corolario o conclusión final, la afirmación del hecho de la preservación de María

96 Ibid., corollarium.

97 El texto anselmiano responde a una pregunta del discípulo Boson sobre la posibilidad de demostrar la necesidad y conveniencia de salvar a los hombres mediante la muerte de Cristo y no de otra manera. San Anselmo entabla el diálogo para demostrarle que cuando no encontramos en Dios ningún inconveniente y cuando hay razón, por pequeña que sea, para hacer una cosa, hemos de admitirla. Y añade: "Sicut enim in Deo quodlibet parvum inconveniens sequitur impossibilitas, ita quamlibet parvam rationem, si maiori non vincitur, comitatur necessitas." (S. ANSELMUS, Cur Deus homo, 1. 1, c. 10: PL. 158, 375).

98 In 3 Sent., d. 3, q. 1, a. 3, ad probationem corollarii.

9. Nos referimos al texto siguiente: "Excepta itaque sancta Virgine Maria, de qua propter honorem Domini nullam prorsus, cum de peccatis agitur, haberi volo quaestionem: unde enim scimus quod ei plus gratiae collatum fuit ad vincendum omni ex parte peccatum, quae concipere ac parere meruit, quem constat nullum habuisse peccatum..." (S. AUGusTinus, De natura et gratia, c. 36, n. 42: PL. 42, 267). 
del pecado original, milita una falange de teólogos de gran valía. Recoge, pues, sus opiniones y las divide en tres grupos.

A la cabeza del primero van Santo Tomás y Egidio Romano ${ }^{100}$. Y como representante del segundo y tercer grupo, Enrique de Gante. Finalmente arguye contra los adversarios de la fiesta de la Inmaculada Concepción de María.

Forzados por los principios de universalidad del pecado y de la redención de Cristo, Tomás de Aquino y Egidio Romano ${ }^{101}$ adoptaron una actitud contraria al privilegio de la Inmaculada. Según ellos, María permaneció por algún tiempo, casi imperceptible, en el pecado original.

"Contra corollarium autem sunt tres opiniones, sive tres modus dicendi doctorum.

Dicunt enim quidam sollemnes doctores -en la nota marginal aparecen los nombres de Santo Tomás y Egidio Romano- quod Virgo Maria in originali peccato concepta fuit, et per aliquod tempus in tali peccato remansit, quamvis cito purgata fuerit. Et hoc probantur multis sanctorum auctoritatibus" 102 .

Las pruebas en que se apoyaban, según Tomás de Strasgbourg, eran precisamente los testimonios de los Santos Padres y Doctores en los que se afirma la universalidad de la redención de Cristo y del pecado origi nal. Testimonios que el Argentinense enumera y refuta a continuación, pero que serán presentados más adelante en el argumento de Tradición, contraponiendo la mentalidad de nuestro autor y de los adversarios de la Inmaculada en la explicación e inteligencia de los mismos.

100 No intentamos prejuzgar la cuestión de si negaron o no la tesis inmaculista; exponemos, no más, el pensamiento de Tomás de Argentina. Sin embargo, creemos que es un dato interesante y positivo, en favor o en contra de una opinión o sentencia, tener en cuenta aquello que pensaron de tal doctrina los contemporáneos del autor, o los que inmediatamente le sucedieron.

Sobre la opinión de Santo Tomás (In 3 Sent., d. 3, q. 1, a. 1; Summ. Theolog., III a, q. 27, a. 1-2; Quodlib. VI, q. 5, a. 7), de la cual tanto se ha disputado y escrito, cfr. P. LUMBRERAS, Saint Thomas and the Immaculate Conception, Indiana 1924; E. EuPIzI, Il pensiero di Tommasso d'Aquino riguardo al dogma della Immacolata Concezione, Roma 1941; R. GarRIGOU-LAGRANGE, La Madre del Salvador. Versión española de José López Navío, Buenos Aires 1947, 53-58; M. Cuervo, "Por qué Santo Tomás no afirmó la Inmaculada": Salmant. 1 (1954) 622-674.

101 Además de Santo Tomás y Egidio Romano suele enumerarse entre los defensores de esta sentencia a ALEXANDER HALENSIs, Summa Theologiae, IIIa, tract. 2, q. 2, m. 2, a. 1-5; S. BonAventurA, In 3 Sent., d. 3, pars. 1, a. 1, q. 2; S. Albertus Magnus, In 3 Sent., d. 3, a. 3-5; Richardus de Mediavilla, In 3 Sent., d. 3, a. 1, q. 1-2; Petrus De TARANTASia, In 3 Sent., d. 3, q. 1, a. 1, etc. 102 Thomas DE Argentina, In 3 Sent., d. 3, q. 1, a. 1, contra corollarium. 
El pensamiento doctrinal de Enrique de Gante en torno al privilegio concepcionista admite, para Tomás de Argentina, dos modalidades. Modalidades que, a nuestro juicio, deduce de las distintas maneras de interpretar la doctrina del "Doctor Solemne" al probar la posibilidad de que María permaneciera en el pecado original sólo de paso y como por un instante.

Enrique de Gante, 1217-1293, no se contentó con las explicaciones que daban sus contemporáneos para justificar la fiesta de la Inmaculada Concepción. Tampoco le convencían las razones y conclusiones de los que negaban el privilegio inmaculista. Así alejándose bastante de éstos, pero sin llegar a afirmar la inmunidad o preservación total, ensayó una teoría original sin llegar a captar la singularidad del privilegio mariano.

María, según él, pudo ser concebida en pecado original en el primer instante de su existencia y santificada inmediatamente después de este instante. Según esto, su santificación habría tenido lugar en un lapso de tiempo intermedio, que debe estar necesariamente interpuesto entre el primer y el segundo instante de su existencia. Esta es la verdadera opinión expuesta por Enrique de Gante, ampliamente defendida por diversos argumentos ${ }^{103}$.

La concepción y explicación del "Doctor Solemne" se difundió rápidamente, dado el ambiente de discusión sobre el privilegio inmaculista. en los centros culturales teológicos y principalmente en París, entonces emporio del saber. Pero su sentencia ocasionó interpretaciones erróneas. Ya Godofredo de Fontaines, † 1306, le acusa de haber defendido la simultaneidad del pecado y de la gracia en el alma de María ${ }^{104}$, si bien Egidio Romano solamente dice que su doctrina llevaría a admitir la simultaneidad de ambas ${ }^{105}$. Posteriormente numerosos teólogos le atri-

103 ENRIQUe DE GaNTe expuso su sentencia en el Quodlib. XV, q. 13. Amplios estudios sobre su doctrina pueden verse en J. M. DE GoICOECHEA, Doctrina mariana de Enrique de Gante, Lima 1944, 40-54; Fr. LEITE DE FARIA, "L'attitude des theologiens au sujet de la doctrine d'Henri de Gand sur la conception de la Sainte Vierge": Etud. franc. 5 (1954) 133-152; "L'opinion d'Henri de Gant sur la Conception de la Sainte Vierge": Mar. 16 (1954) 290-316.

104 Godofredo DE FonTAINES, Quodlib. VIII, q. 4; Cfr. J. HoFFmans, "Le huitieme quodlibet de Godofraid de Fontaines": Les Philosophes belges IV, fasc. 1, Louvain 1924.

105 AEgidius Romanus, Quodlib. VI, q. 20: "Dicitur enim quod B. Virgo fuit in originali concepta... tamen non stetit in originali nisi per instans... Sed si haec possitio est vera, quantum nobis occurrit, cogeremur ponere quod quaestio quaerebat, videlicet, quod simul fuisset sub culpa et sub gratia". 
buyeron esta opinión, exponiendo y refutando sus argumentos ${ }^{106}$. Tomás de Argentina es uno de ellos.

Tomás de Strasbourg, espíritu genuinamente filosófico, no teme hacerse pesado en la exposición de las razones con las que Enrique de Gante trata de confirmar su sentencia y en la refutación de las mismas. Hasta parece sentirse satisfecho y lleno de gozo al refutar al "Doctor Solemne". Postura fácilmente explicable, pensamos, por aquella conciencia de Escuela que reinaba entre los doctores agustinos de los siglos xiI y xiv. Enrique de Gante fue uno de los más decididos adversarios de Egidio Romano, y Tomás de Argentina trataría de sacarse la espina aprovechando esta oportunidad - lo hace con mucha frecuencia- para ensalzar, aunque sólo fuera indirectamente, al Maestro de la Escuela Agustiniana, Egidio Romano.

Prolijo, por tanto, en razones y argumentos, recoge separadamente ambas opinones y ensarta una serie de pruebas en contra del "Doctor Solemne".

Primeramente comienza refutando la opinión erróneamente atribuída a Enrique de Gante: que la gracia y la culpa existieron simultáneamente en el alma de María en el primer instante de su existencia. En confirmación de esta sentencia aduce razones de los primeros expositores - principalmente de Godofredo de Fontaines - contrarios a la doctrina del "Doctor Solemne": la división del instante en signos o tiempos distintos del mismo instante para probar que efectivamente la gracia y la culpa, el expelente y lo expulsado, existieron simultáneamente en el alma de María. En aquel instante María tuvo el pecado original, ser primero y último a la vez, aunque según distintos tiempos del mismo instante, ya que, por ser término del tiempo pretérito, tuvo en él primer ser; por ser principio del tiempo siguiente, tuvo en él último ser, debido al impulso siguiente de la gracia que la empujaba del anterior al siguiente instante ${ }^{107}$.

106 Así, v. gr., JUAN DE PouILLY, 1321, Quodlib. III, q. 3, a. 2; DuRANDo DE SaInT-Pourcain, In 3 Sent., d. 3, q. 2 ; Herveus Natalis, Quodlib, VII, q. 22 ; JUAN DE BASSOLIS, In 3 Sent., d. 3, q. 2 ; JUAN BaCONTHoRP, In 3 Sent., d. 3 , q. 2, a. 1; MARSILIUS D'INGHEN, In 2 Sent., d. 20, a. 1; a. 1, etc.

107 "Secundus modus dicendi -en la nota marginal pone el nombre de Enrique de Gante- contrarius supradictis est: quod Virgo fuit concepta in originali peccato, et tamen in primo instanti, in quo fuit concepta, statim fuit sanctificata.

Ad cuius declarationem isti doctores dicunt, instans temporis divisibile esse in tria signa, puta, A. B. C. In primo igitur signo, puta, in A. fuit originalis 
Sin vacilación alguna el Argentinense reprueba esta sentencia. Falla en su base porque realmente admite la existencia del pecado original de María, aunque sea durante un instante, que es lo que se trata de negar. Más aún: filosóficamente y teológicamente, el modo de explicar esa sentencia es imposible.

Sus argumentos siguen el ritmo marcado por Erveo Natal, $\uparrow 1323$, y Durando de Saint-Pourcain de los que depende en gran parte ${ }^{108}$. Como éstos, nuestro autor distingue dos hipótesis: si se admite que esos signos del instante son realmente divisibles, es absurda la afirmación anterior, ya que todos estiman que el instante es realmente indivisible. Si son divisibles solamente "ratione", es lo mismo, porque, aunque "ratione" la culpa y la gracia no existieran simultáneamente en María, en la realidad sería un solo y mismo signo ${ }^{109}$.

Además, dada la indivisibilidad del instante "secundum rem", la culpa, que existía en el primer signo, también existiría en el tercero. $\mathrm{Y}$ la gracia que existía en el tecer signo, existiría también en el primero ${ }^{110}$. Por lo demás, que el expelente y lo expulsado deban existir simultáneamente en el mismo instante, no es cierto tratándose de un expe-

culpa in anima Virginis sine gratia sanctificationis. In B. fuerunt gratia et culpa simul non in esse perfecto: sed quasi in quodam transitu: quia quamvis culpa, et gratia cum sint opposita, non possint esse simul in esse permanenti, et completo, possunt tamen esse simul in transitu, et secundum esse incompletum. In tertio signo, puta in C., fuit gratia secundum esse habituale et permanens, seu completum, et expulsa est culpa totaliter. Quod autem culpa et gratia sint simul in anima modo praedicto, ipsi probant sic: expellens et expulsum oportet esse simul; gratia est culpa expulsiva : ergo, etc." (THOMAS DE ARGENTINA, In 3 Sent., d. 3, q. 1, a. 1, opinio secunda contra corollarium).

108 Herveus Natalis, $l$. $c$. ; DURANDo DE SaINT-Pourcain, $l$. $c$. Rehusamos transcribir sus argumentos por la excesiva amplitud de los mismos.

1091 "Sed ista positio non solum deficit in hoc, quod ponit Virginem in originali peccato fuisse conceptam: verum etiam modus ponendi impossibilis esse videtur. Quia secundum quod ab aliquibus dicitur, et bene, illa divisio instantis in signa, aut est divisio in plura secundum rem, et realiter differentia: aut secundum rationem tantum. Si primo modo, tunc indivisibile secundum rem erit divisibile secundum rem: quia per instans omnes veri philosophi intelligunt mensuram indivisibilem. Si secundo modo, tunc gratia et culpa erunt simul in eodem subiecto secundum suum esse perfectum pro eadem indivisibili mensura secundum rem, et per consequens pro eodem signo secundum rem, quod etiam secundum te est impossibile" (In 3 Sent., d. 3, q. 1, a. 1, contra secundam opinionem).

${ }_{110}$ "Praeterea, quando aliqua plura sunt idem secundum rem, quidquid est in uno realiter, hoc similiter est in altero realiter, et quidquid non est in uno realiter, non est in altero realiter. Sed primum signum instantis et ultimum sunt idem realiter. Da oppositum: tunc erit dare minus minimo in mensuris realibus, quod est impossibile. Ergo culpa, quae secundum te est realiter in primo signo, erit realiter in tertio signo ${ }_{f}$ quod tu negas; et gratia, quae est realiter in tertio signo, erit realiter in primo signo, quod similiter negas" (Ibid.). 
lente formaliter, cual es la gracia con respecto a la culpa, las cuales se excluyen mutuamente ${ }^{111}$.

La verdadera opinión de Enrique de Gante, que María permaneció por un solo instante en pecado e inmediatamente fue santificada, le expone y refuta Tomás de Argentina en el tercer grupo de los adversarios a la Inmaculada. Con precisión y maestría expone su pensamiento capital y enuncia algunos de sus argumentos -el movimiento y cambio de la alubia al ser molida, la conveniencia de librar a María del pecado lo antes posible, etc. ${ }^{112}$.

Algunos contemporáneos del "Doctor Solemne", como Durando de Saint-Pourcain ${ }^{113}$ y Roberto de Cowthon ${ }^{114}$, recibieron con aplauso su doctrina y nuevamente ensayaron pruebas para confirmarla.

111 "Praeterea, isto modo nullus unquam nec sibi ipsi, nec alteri contradiceret; quia affirmatio potest verificari pro uno signo, et negatio pro alio signo. Nec ratio istorum concludit: quia quamvis effective expellens aliquo modo sit simul cum expulso, hoc tamen non est verum de formaliter expellente: quia talis expellentis positio est exclusio ipsius expulsi, et istius praesentia est illius absentia: et ideo talia numquam sunt simul; unde quamvis ex talibus quandoque componatur media qualitas, in qua secundum suas virtutes simul sunt, numquam tamen secundum suum esse formale simul esse possunt. Cum ergo gratia sit culpae expulsiva non effective sed formaliter; nec ex culpa et gratia possit aliquod unum componi medians inter eas: ideo culpa et gratia nullo modo possunt esse simul, sicut nes quaecumque alia contradictoria.

Forte dicetur, quod culpa et gratia non sunt opposita contradictorie, sed solum privative.

Respondeo, quod hoc habeo pro eodem: quia oppositio privativa includit contradictoriam, quamvis non e converso. Sed ubicumque inclusa non possunt esse simul, ibi nec includentia potuerunt simul esse, cum tota causa repugnantiae inclusorum reservetur in ipsis includentibus" (Ibid.).

112 "Tertius modus contrarius supradictis est, quod fuit Virgo in originali peccato per unum completum in instans, et solum per illud instans: quia in toto tempore copulato ad illud instans fuit in gratia. Et istum modum quandoque etiam ponit doctor ille, qui posuit secundum modum. Et quod illud sit possibile, ipsi probant sic: virtute naturae potest fieri, quod aliquid in una actuali dispositione maneat per unum solum instans: ergo et virtute divina hoc fieri potest. Consequentia patet: Antecedens probatur: quia si fabae motae sursum in ultimo instanti sui motus, quo attingit terminum ad quem, occurrat lapis molaris descendens deorsum, tunc faba in termino sui motus manebit solum per instans: quia si maneret per tempus, necessario oporteret lapidem molarem quiescere.

Praeterea, decuit filium tam cito matrem a peccato liberare, quam cito hoc fuit possibile; sed si plus quam per instans ipsa fuisset in isto peccato, tunc non fuisset ita cito liberata, sicut fuit possibile eam liberari: quia cum tempus sit divisibile in infinitum, ideo in quacumque parte temporis ipsa fuisset sanctificata, ante illud tempus potuit sanctificari" (Ibid., opinio tertia contra corollarium).

${ }_{113}$ In 3 Sent., d. 3, q. 2; "His tamen non obstantibus prior opinio videtur verior, scilicet quod Deus potuit facere quod beata Virgo per solum instans esset in originali culpa, et toto tempore sequenti in gratia".

114 "...nulla contradictio includitur si ponamus quod Deus faceret quod anima beatae Virginis tantum per unum instans fuerit in culpa et per totum tempus sequem in gratia. Ideo concludo quod hoc Deo sit possibile..." (In 3 Sent., d. 3, q. 1). Cfr. C. Balic, IoAnnis DE Polliaco et Ioannis DE Neapoli, 
Tomás de Argentina - sin citar nombres- trae a colación una de estas, que pertenece al dominico Durando. Si Dios puede hacer que la gracia exista sólo durante un instante en el alma, también el pecado puede existir o permanecer un solo instante. Dios, cuya acción no es sucesiva, puede por su libre voluntad producir en un sujeto una disposición diversa, cual es la gracia respecto al pecado, inmediatamente después de un instante ${ }^{115}$.

Expuesta la doctrina verdadera de Enrique de Gante y de sus seguidores, Tomás de Strasbourg entabla el diálogo con ellos. Primero arguye contra Durando: la forma permanece, cual es la gracia y la culpa, difiere de la forma sucesiva en que debe existir "ratione", al menos durante dos instantes. María, pues, en caso de ser concebida en pecado, como vosotros decís, hubiera permanecido en él durante más de un instante ${ }^{116}$.

Por otra parte, puesto que la gracia se infunde en un instante -así lo afirmáis vosotros- y la culpa existió en María durante un instante, o concedéis que hubo un lapso de tiempo intermediario entre ambos, en cuyo caso María hubiera permanecido en pecado también durante este espacio de tiempo, cosa que negáis vosotros; o negáis la existencia de ese lapso de tiempo intermedio. Pero en este caso resultarían dos instantes inmediatamente seguidos, y así desaparecería la continuidad de tiempo, lo cual es imposible ${ }^{117}$. Como advierte muy bien Tumminello,

Quaestiones disputatae de Immaculata Conceptione B. Mariae Virginis. (Bibliotheca Mariana Medii Aevi, 1, Sivenici 1931) XLVI, de donde hemos tomado el texto.

115 "Et illud confirmat quidam alius sic: Deus potest facere, quod aliquis per solum instans sit in gratia, et per totum tempus sequens sit sine gratia: ergo e converso poterit facere, quod aliquis per solum instans sit in culpa, et toto tempore sequenti sit in gratia. Antecedens probant: quia agens per voluntatem libere, cuius actio non est successiva, potest per unum solum instans agere, et per totum tempus sequens ab agendo cessare; sed Deus infundendo gratiam agit per voluntatem libere, et eius actio non est successiva: ergo, etc. Consequentia similiter probant: quia recessus a culpa in gratiam non est per motum, sed per simplicem gratiae influentiam: sicut etiam recessus a gratia in culpam non est per motum, sed per huiusmodi simplicis gratiae substractionem: ideo nihil repugnat uni, quod non repugnat alteri" (In 3 Sent., d. 3, q. 1, a. 1, opinio tertia contra corollarium).

116 "Sed nec ista pallatio valet: quia in hoc videtur differre forma permanens et successiva: quia forma permanens ad minus per dua instantia aequaliter se habet, puta nunc, sicut prius, quod impossibile est dare in forma successiva. Cum igitur gratia sit forma permanens: ideo de sui ratione est, quod ubicumque ponitur, maiorem habeat durationem, quam per unum solum instans. Et eodem modo dico de culpa sibi opposita" (Ibid., contra tertiam opinionem).

117 "Praeterea, secundum istos, gratiae infusio fit in instanti; aut ergo inter instans, quo isti dicunt Virginem fuisse in culpa originali, et instans, quo gratiae infusionem recepit, fuit tempus medium, aut non. Si primo modo, tunc, 
el nudo de la cuestión está en la noción de tiempo y en su relación con el instante ${ }^{118}$.

Al ejemplo de la alubia, aducido por Enrique de Gante, Tomás de Argentina responde que nada prueba, ya que se trata de un movimiento que se mide en el tiempo y no en el instante. Además, en el caso de la infusión de la gracia, es preciso que el tiempo siga al instante. Sería, sin embargo, inconveniente que el instante siguiera al instante, como ha dicho antes ${ }^{119}$.

Y si Enrique de Gante estima que convino al Hijo de Dios librar a su Madre, María, de la culpa hereditaria cuanto antes pudo, es decir, después del primer instante de estar en pecado, el "Doctor Fácil" le contesta que más decoroso y conveniente fue preservarla del mismo ${ }^{120}$.

Después de exponer estas razones contra Enrique de Gante, Tomás de Strasbourg vuelve sobre sus pasos. Y de nuevo se entretiene con $\mathrm{Du}$ rando. No comprende cómo Dios puede hacer que alguien esté en gracia sólo por un instante y sin gracia durante todo el tiempo siguiente. Porque si la gracia sólo existe por un instante, en todo el tiempo restante será pura nada; y si deja de existir en el tiempo, entonces no tuvo el ser en un instante. Por tanto, aunque Dios obre libremente y su acción no sea sucesiva, no puede producir una cosa que solamente tenga el ser durante un instante único. Tal cosa solamente sería ser en potencia, pero no en acto. E inmediatamente hace la aplicación al caso de María: si María hubiese estado en pecado original solamente por un instante $e$ inmediatamente le hubiera sido infundida la gracia, forma contraria al pecado, nunca hubiera incurrido en pecado actualiter, sino sólo potentialiter. Y eso lo concede el Argentinense: que en María existió posibilidad de contraer la culpa hereditaria, posibilidad que nunca llegó a

cum etiam secundum eos culpa non expellatur nisi per gratiae infusionem, igitur Virgo gloriosa fuisset non solum per instans, sed per totum tempus medium in culpa originali. Si secundo modo, tunc duo instantia immediate consequenter se haberent, quod est impossibile" (Ibid.).

118 G. TUMminello, L'Immacolata Concezione di Maria e la Scuola Agostiniana del secolo XIV, Roma 1942, 22.

119) "Et per hoc patet solutio ad primum motivum eorum, quod recessus fabae ab ubi, quod acquisivit in ultimo sui proprii motus termino, est per modum lapidis descendentis, qui quidem motus non mensuratur instanti sed tempore. Non est autem inconveniens: sed est necessarium, quod tempus sequatur immediate ipsum instans, quamvis sit inconveniens quod instans sequatur ipsum instans, sicut esset in proposito, eo quod infusio gratiae instanti mensuretur" (Ibid.).

120 "Ad secundum dicendum quod magis decuit filium matrem praeservare a peccato, quam post peccatum liberare; et hoc etiam videtur esse inconveniens modo, quo dixi superius" (Ibid.). 
actualizarse, gracias al poder y bondad divinas, que la preservaron o previnieron para que no quedara sometida a la culpa, como los demás hombres ${ }^{121}$.

El intento del "Doctor Solemne", que era justificar la fiesta de la Inmaculada Concepción, en ninguna manera pudo ser expuesto con menor éxito y acierto. Tratando de probar la santidad inicial de María en su Concepción, comienza afirmando su existencia en pecado en el primer instante de su ser. De ahí que el Argentinense le atribuya también el haber negado el verdadero sentido de esta fiesta. Y si bien sus afirmaciones van dirigidas principalmente contra Durando, que defendía la denominación de fiesta de la santificación de María y no de la Concepción, también abarcan de algún modo las conclusiones de Enrique de Gante. Aunque sería ahora el lugar apropiado para su exposición, las estudiaremos como apartado aparte bajo el nombre de "argumento litúrgico".

121 "Ad tertium dicendum, quod antecedens non videtur esse verum: quia si per solum instans esset gratia, tunc non appareret, quo modo posset desinere: quia in illo instanti non posset desinere esse, quia in eo incepit esse; nihil autem desinit in eadem indivisibili mensura, qua incepit esse, nec in aliqua parte temporis sequentis: quia si solum per instans habet esse, tunc toto tempore sequent erit purum nihil; sed quod est purum nihil, non desinit esse: quia omne, quod desinit esse, oportet, quod aliquo modo habeat esse, a quo recedens desinit esse: ergo si in tempore desinit esse, tunc non habuit esse solum per instans.

Ad probationem dicendum, quod quamvis Deus libere agat $t_{\text {s }}$ et eius actio non sit successiva: tamen effectus non patitur, quod aliqua natura, quae est res permanens, producatur, quae solummodo habeat esse per unicum instans: talis enim natura non esset actu ens, sed solum potentia... Si aliquid motum ad albedinem statim moveretur ad formam oppositam, in illo subiecto non esset albedo nisi in potentia. Sic in proposito, si in beata Virgine fuisset originale peccatum per solum instans, et statim mota fuisset, seu mutata ad formam contrariam, puta ad gratiam, ipsa numquam fuisset in tali peccato actualiter, sed solum potentialiter: quod nec ego, iuxta ea quae dixi superius, nego; habuit enim beata Virgo in sua origine possibilitatem ad praedictam maculam, licet talis possibilitas potentia divina praeventa, numquam ad actum fuerit reducta" (Ibid.). 